\title{
PROPIONIC ACID IS AN ALTERNATIVE TO ANTIBIOTICS IN POULTRY DIET
}

\author{
M. N. Haque, R. Chowdhury, K. M. S. Islam and M. A. Akbar ${ }^{1}$
}

\begin{abstract}
Propionic acid (PA) is a fungicide and bactericide, registered to control fungi and bacteria in stored grains, hay, grain storage areas, poultry litter, and drinking water for livestock and poultry. European Union (EU) certifies PA as the great of grain preserver and most efficient in controlling Salmonella and other pathogens. Recently it is used as feed additive in poultry and non-ruminant production. Suitable inclusion level of PA is 0.2 to $0.4 \%$ which can improve the overall performances of poultry. The preservative effect of PA is due to its antibacterial and mould inhibitory effect. High bacteriostatic property of PA is due to its $\mathrm{pH}$ reduction activity both in feed and gastrointestinal tract through pharmacogenic action on microflora. Propionic acidA with its growth promoting, health enhancing and antimicrobial effect has proven to be an effective alternative to antibiotic growth promoters in food animal production.
\end{abstract}

Key word: Propionic acid, Preservatives, Growth promoter, Poultry

\section{Background}

Organic acids have been used for decades in feed preservation, protecting feed from microbial and fungal destruction and increase the preservation effect of fermented feed, e.g. silages. It has also been used as antimicrobial feed additives for long times. The objective of dietary acidification is the inhibition of intestinal bacteria of those both pathogenic and competing with the host for available nutrients and reduction of possibly toxic bacterial metabolites, e.g. ammonia and amines. Acidification increases gastric proteolysis, protein and amino acid digestibility and utilization of minerals and thus improving performance of the animal. Among organic acids, propionic acid (PA) is an effective element used as antimicrobial feed additive as well as preservatives. Although it is useful as additive, it is extensively used as feed preservatives and less as feed additives. The purpose of this review is to focus on the specific effects of PA on the health and performance of poultry and other avian species.

\section{Propionic acid}

Propionic acid (PA) is a naturally occurring carboxylic acid. It was derived from the Greek words protos = "first" and pion = "fat," because it was the smallest $\mathrm{H}\left(\mathrm{CH}_{2}\right) n$ $\mathrm{COOH}$ acid that exhibited the properties of the other fatty acids, such as producing an oily layer when salted out of water and having a soapy potassium salt. Propionic acid was first described in 1844 by Johann Gottlieb, who found it among the degradation products of sugar. In pure state, it is a colorless, corrosive liquid with a sharp, somewhat

Department of Animal Nutrition, Bangladesh Agricultural University, Mymensingh-2202, Bangladesh

(Received: August 05, 2009) 
Bang. J. Anim. Sci. 2009, 38(1\&2)

unpleasant odor. It is produced biologically as its coenzyme-A ester, propionyl-CoA and from the bacteria (Propionibacterium sp.) as the end product of their anaerobic metabolism.

\section{Uses of propionic acid}

Propionic acid inhibits the growth of mold and some bacteria. As a result, most PA produced is used as a preservative for both animal feed and food for human consumption and the most effective use of it as growth promoter and feed additive in food animals especially poultry and pig. For animal feed, it is used either directly or as its ammonium salt. Uses of antibiotics have a great threat as it create microbial resistance after long-term use which create a serious health problem. Antimicrobial feed additives such as PA is effective to antibiotic growth promoters for safe animal products as well as human health. Propionic acid is also useful as a chemical intermediate. It can be used to modify synthetic cellulose fibers. It is also used to make pesticides and pharmaceuticals. The esters of PA are sometimes used as solvents or artificial flavorings (http://en.wikipedia.org/wiki/propionic_acid).

\section{Physical and chemical properties of propionic acid}

\begin{tabular}{|c|c|}
\hline Parameters & Properties \\
\hline IUPAC* name & Propionic acid \\
\hline Structural formula & $\mathrm{CH}_{3}-\mathrm{CH}_{2}-\mathrm{C}_{\stackrel{\mathrm{O}}{\mathrm{H}}}^{\mathrm{C}}$ \\
\hline Chemical formula & $\mathrm{C}_{3} \mathrm{H}_{6} \mathrm{O}_{2}$ \\
\hline Appearance & Colorless liquid \\
\hline Melting point & $252 \mathrm{~K}\left(-21^{\circ} \mathrm{C}\right)$ \\
\hline Boiling point & $414 \mathrm{~K}\left(141^{\circ} \mathrm{C}\right)$ \\
\hline Acidity $\left(\mathrm{p} K_{\mathrm{a}}\right)$ & 4.88 \\
\hline Density & $0.99 \mathrm{~g} / \mathrm{cm}^{3}$, liquid \\
\hline Flash point & $55^{\circ} \mathrm{C}$ \\
\hline Auto ignition temperature & $475^{\circ} \mathrm{C}$ \\
\hline Solubility in water & miscible \\
\hline Acute effects & $\begin{array}{l}\text { Corrosive. Contact with concentrated liquid can result in permanent } \\
\text { damage to skin, eyes, or digestive tract. }\end{array}$ \\
\hline Chronic effects & None \\
\hline Main hazards & Corrosive \\
\hline
\end{tabular}

*IUPAC = International Union of Polymer and Applied Chemistry

Source: (http://en.wikipedia.org/wiki/propionic_acid)

\section{Propionic acid in avian diet}

Propionic acid has an effective mould inhibitory and bacteriostatic action. This property makes it well suited for use as a preservatives agent in human food. Propionic acid is 
also used successfully in poultry feed to prevent digestive disorders. The positive effects of PA as feed additive can be explained by several working mechanisms. This acid can break down the DNA (deoxyribonucleic acid) structure in the bacterial cell nucleus and as a result the bacterial cell can no longer divide or may even die. Certain bacteria are sensitive to $\mathrm{pH}$, e.g. E. coli, Salmonela spp., Listeria monocytogenes, Clostridium perfringens, while others are not, e.g. Bifidobacteria, Lactobacillus spp. Reduction of the $\mathrm{pH}$ value in the stomach by addition of PA in feed inhibits bacterial growth as well as improves performances.

\section{Effect of PA on productive parameters of avian species Growth}

The mechanism of growth promotion of PA is seems to be the reduction of pathogenic burden by reducing gut $\mathrm{pH}$, increasing digestibility, improving the permeability of the intestinal mucosa and thus increase the rate of absorption and also increase the utilization of protein, amino acids, minerals and other nutrients. Additions of Luprosil ${ }^{\circledR}$ NC (containing 53.5\% PA) @ 0.4\% showed significant body weight gain of broiler chicken at 49 days of age compared to unsupplemented group (Izat et al., 1990). An experiment with organic acid salt $(1 \mathrm{~g} / \mathrm{kg}$ each of calcium propionate, ammonium formate and calcium lactate) as substitute for antibiotics (virginiamycin @ $0.5 \mathrm{~g} / \mathrm{kg}$ as antibiotic) showed numerically higher live weight and live weight gain in organic acid salt supplemented group compared to antibiotic supplemented group (Paul et. al., 2007).

Marcos et al. (2004) reported that broiler fed organic acid mixture (70\% formic acid and $30 \%$ PA) @ 0.25 and $0.50 \%$ with diet showed higher gain compared to birds fed higher level (1.0 and 2.0\%) organic acid mixture. Significant improvement in body weight and weight gain of turkey poult by supplementing MC (Myco curb containing PA) @ 0.625 and $1.25 \%$ was reported by Roy et al., (2002).

\section{Feed intake and feed conversion}

As feed preservatives PA reduces the $\mathrm{pH}$ of feed, it improves the hygienic condition of feed and improves palatability which ultimately increases feed intake but higher level also reduces feed intake. Cave (1984) reported that when PA was included in the feed up to levels of $100 \mathrm{~g} / \mathrm{kg}$, from 0 to 28 days, voluntary feed intake of broiler chicks was decreased with increasing dietary levels of acid. Organic acid salt (calcium propionate, ammonium formate and calcium lactate @ 1 $\mathrm{g} / \mathrm{kg}$ ) as an alternative to antibiotic (virginiamycin@ @ $0.5 \mathrm{~g} / \mathrm{kg}$ ) showed that the cumulative feed intake in broiler was significantly higher in antibiotic treated group than other, whereas improved feed conversion ratio (FCR) was found in organic acid salt supplemented group (Paul et. al. 2007). In a study, Celik et al. (2003) observed better FCR of turkey chicks supplemented with organic acids (propionic caid, formic acid, acetic acid) as compared to unsupplemented group. Propionic acid increases feed intake by improving palatability of feed and may increase permeability of mucosal cell of the intestine which increases the rate of utilization of nutrients and results better feed conversion. 


\section{Carcass yield}

It is well established that PA used as growth promoter improve the rate of utilization of al nutrient especially protein which results better dressing percentage. Female broilers fed $7.3 \mathrm{~kg} /$ ton $(0.8 \%)$ of Luprosil ${ }^{\circledR}$ NC (53.5 \% PA) resulted in a significant improvement in carcass dressing percentage (Izat et. al., 1990). Significant effect on carcass yield of broiler chicken fed diet supplemented with PA was reported by Hume et al. (1993).

\section{Antibacterial effect of propionic acid}

The antimicrobial activity of PA is related to the reduction of $\mathrm{pH}$, as well as its ability to dissociate because it is lipid soluble in the undissociated form, in which it is able to enter the microbial cell. The pH level in specific areas of the gastro intestinal tract (GIT) is a factor which establishes a specific microbial population, and also affects the digestibility and absorptive value of most nutrients. Most of the pathogens grow in a pH close to 7 or slightly higher. In contrast, beneficial microorganisms live in an acidic pH (5.8-6.2) and compete with pathogens (Ferd, 1974). In addition, lowering the $\mathrm{pH}$ by organic acids reduce the pathogenic microbes from GIT and improves nutrient absorption (Boling et al., 2001).

Lower $\mathrm{pH}$ values of crop and gizzard contents were found in broiler fed acidifier FA 30 (PA+CA) with diet compared to control group (Andrys et al. 2003). It has been reported that the inclusion of formic and PA in the form of Bio-add ${ }^{\mathrm{TM}}$ to the feed of hens made no difference to the $\mathrm{pH}$ of the intestinal tract, but resulted in higher concentrations of these acids in the contents of the crop and gizzard. Effectiveness of MC (Myco curb containing PA) against various bacteria and fungi was reported by several scientists (Kemin Industries, 1988 and 1993 and Hume et al., 1993).

Propionic acid effectively inhibits the growth of $E$. coli bacteria in the animal's gastrointestinal tract. At the same time it does not inhibit the growth of Lactobacillus bacteria. Previous research by Mathew et al. (1991) found that when Luprosil NC was fed to growing pigs, the population of gastrointestinal $E$. coli bacteria decreased, Lactobacillus bacteria increased. The $\mathrm{pH}$ of digesta decreased, due to the shift in microbial fermentation from the modified bacterial population.

Addition of PA in feed has a potential role in reducing Salmonella spp. in the chicken intestine. Kwon et al. (2003) reported buffered propionic acid (BPA) markedly decrease the growth of Salmonella and other intestinal anaerobic microbes by decreasing $\mathrm{P}^{\mathrm{H}}$ from 7 to 5 and maximum inhibitory effect was found at 3\% level of BPA in broiler. The results of this study indicated that the growth inhibitory effect of PA against S. typhimurium strains was enhanced by a decrease in $\mathrm{pH}$ and suppressed by anaerobiosis, suggesting that the growth response of $S$. typhimurium to PA in the chicken intestine might be affected by the environmental conditions such as $\mathrm{pH}$ and anaerobiosis. The minimum inhibiting concentration (MIC) of PA is well researched and publicized (Table 1). 
Table 1. The minimum inhibiting concentration (MIC) of propionic acid on bacteria

\begin{tabular}{|l|c|}
\hline \multicolumn{1}{|c|}{ Test-organisms (Bacteria) $\mathbf{1}^{\mathbf{1}}$} & MIC \% of propionic acid \\
\hline Staphylococcus aureus & 0.25 \\
Bacillus subtilis & 0.25 \\
Aerobacter aerogenes & 0.50 \\
Escherichia coli & 0.25 \\
Escherichia freundii & 0.125 \\
Proteus vulgaris & 0.2 \\
Pseudomonas aeroginosa & 0.25 \\
Pseudomonas fluorescens & 0.25 \\
Serratia marcescens & 0.25 \\
\hline
\end{tabular}

${ }^{1}$ Standard broth pH 7.0-7.2

Source: BASF Corporation, 1998

\section{Propionic acid as mould inhibitor and preservatives}

Fungal inhabitations in feedstuffs during storage seem to be inevitable without the presence of effective preservative(s) if the humidity is over $16 \%$ with atmospheric temperature higher than $20^{\circ} \mathrm{C}$ (Ronald, 1996). The fungal growth on feed can decrease substantially its quality as the moulds thriving there in consuming majority of fat, protein, carbohydrate and even mineral elements, leading subsequently to stuff discolorations, heating, mustiness and biochemical transformations yield the accumulation of toxic substances in most cases. The presence of growing moulds and produced mycotoxins in feedstuff decreases feed intake, efficiency and rate of feed, while increasing the risk of infection and reproduction disability (Lin and Chen, 1995). The fungal toxins such as aflatoxins, zearalenone, ochratoxin and fumonisin, among those aflatoxins are dominant (Hamilton, 1985 and Zou et al., 1997). The strategy for the control of mould growth, suitable for feed industry, is the careful application of antifungal preservative(s) (Holmquist et al. 1983 and Hamilton, 1985). An ideal feed preservative must be efficacious, inexpensive, corrosion-free and safe to the animal (Holmquist et al. 1983 and Lin and Chen, 1995). However, the preservatives available today are mainly synthetic chemicals such as propionate as well as acetic, sorbic and formic acids (Goering and Gordon, 1974 and Bartov, 1983).

Propionic acid has been proven to show the broadest efficacy among all organic acids against fungi and yeasts (Table 2 and 3). Therefore the most efficient way to keep compound feed at a high hygienic status is the use of PA. The most eco-efficient feed grain preservation method is the treatment with Luprosil (53.5\% PA). Bacteria and yeast contamination in compound feed have a negative impact on the intestinal flora, resulting in nutrient losses and negatively influencing the feed intake of animals. High microbial counts in feedstuffs not only result in a reduced nutrient value, but they also have a negative impact on palatability, which consequently results in a reduced feed intake and 
Bang. J. Anim. Sci. 2009, 38(1\&2)

performance. To avoid these problems animal feed products have to be free of mold and have a long storage life. For this PA is an ideal animal feed preservative.

Table 2. The minimum inhibiting concentration (MIC) of propionic acid on fungi

\begin{tabular}{|l|c|}
\hline \multicolumn{1}{|c|}{ Test-organisms (Fungi) $^{\mathbf{1}}$} & MIC \% of propionic acid \\
\hline Aspergillus niger & 0.25 \\
Aspergillus flavus & 0.25 \\
Aspergillus versicolor & 0.50 \\
Chaetomium globosum & 0.125 \\
Penicillium expansum & 0.125 \\
Penicillium funiculosum & 0.125 \\
Penicillium spinulosum & 0.10 \\
Penicillium roqueforti & 0.125 \\
\hline
\end{tabular}

${ }^{1}$ Sabouraud broth pH 5.0

Source: BASF Corporation, 1998

\section{Safety of propionic acid}

The chief danger from propionic acid is chemical burns that can result from contact with the concentrated liquid. In studies on laboratory animals, the only adverse health effect associated with long-term exposure to small amounts of PA has been ulceration of the esophagus and stomach from consuming a corrosive substance. No toxic, mutagenic, carcinogenic, or reproductive effects have ever been observed. In the body, PA is readily metabolized, so it does not bioaccumulate (http://en.wikipedia.org/wiki/ propionic_acid).

Table 3. The minimum inhibiting concentration (MIC) of propionic acid on yeasts

\begin{tabular}{|l|c|}
\hline \multicolumn{1}{|c|}{ Test-organisms (Yeasts) $^{\mathbf{1}}$} & MIC \% of propionic acid \\
\hline Candida albicans & 0.25 \\
Candida krusel & 0.25 \\
Mansenula anomala & 0.25 \\
Pichia fermentans & 0.25 \\
Oidinum sp. & 0.25 \\
Saccharomyces cerevisiae & 0.25 \\
Saccharomyces vini & 0.25 \\
\hline
\end{tabular}

${ }^{1}$ Sabouraud broth pH 5.0

Source: BASF Corporation, 1998.

\section{Conclusion}

As an antimicrobial feed additive, PA is efficient than that of other organic acids. It creates favorable response on performance and overall health condition of avian 
species. It is also popular as preservatives. Furthermore, like antibiotic growth promoter it has no risk of microbial resistance. Therefore PA with its performance and health enhancing properties is an effective alternative to feed antibiotics in food animal production.

\section{Literature Cited}

Bartov, I. 1983. Effects of propionic acid and of copper sulfate on the nutritional value of diets containing moldy corn for broiler chicks. Poult. Sci., 62: 2195-2200.

BASF Fine Chemicals, 1998. Effect of Luprosil ${ }^{\circledR} N C$ on the gut E. coli of broilers. BASF Corporation, 3000 Continental Drive North, Mount Olive, New Jersey 07828-1234.

Boling, S. D., Snow, J. L., Parsons, C. M. and Baker, D. H. 2001. The effect of citric acid on calcium and phosphorus requirements of chicks fed corn soybean meal diets. Poult. Sci., 80: 783-788.

Cave, N. A. 1984. Effect of dietary propionic and lactic acids on feed intake by chicks. Poult. Sci., 63: 131-134.

Celik, K., Ersoy, I. E., Uzatici, A. and Erturk, M. 2003. The using of organic acids in California turkey chicks and its effect on performance before pasturing. Int. J. Poult. Sci., 2: 446-448.

Ferd, D. J. 1974. The effect of microflora on gastrointestinal pH in the chick. Poult. Sci., 53: 115-131.

Goering, H. K. and Gordon, C. H. 1974. Chemical acids to preservation of high moisture feeds. J. Dairy Sci., 56: 1347-1351.

Hamilton, P.B. 1985. Factors influencing activity of fungi and antifungal agents in poultry feed. In: Trichothecenes and Other Mycotoxins ed. Hamilton, P.B. ed. pp. 207-218. New York.

Holmquist, G. U., Walker, H.W. and Stahr, H. M. 1983. Influence of temperature, pH, water activity and antifungal agents on growth of Aspergillus flavous and Aspergillus parasiticus. J. Food Sci., 48: 778-782.

Hume, M. E., Corrier, D. E., Ivie, G. W. and Deloach, J. R. 1993. Metabolism of propioniic acid in broiler chicks. Poult. Sci., 72: 786-793

Izat, A. L., Tidwell, N. M., Thomas, R. A., Reiber, M. A., Adams, M. H. Colberg, M. and Waldroup, P. W. 1990. Effects of a buffered propionic acid in diets on the performance of broiler chickens and on microflora of intestine and carcass. Poult. Sci., 69: 818-826.

Kemin Industries, 1988. Inhibitory effects of Mycocurb on various bacterial species. Publication No. 02326. Kemin Industries, Inc., Des Moines, IA.

Kwon, Y. M., and Ricke, S. C. 2003. Induction of acid resistance of Salmonella typhimurium by exposure to shortchain fatty acids. Applied and Environ. Microbio. 64: 3458-3463.

Lin, C. D. and Chen, T. C. 1995. Relative antifungal efficacies of phosphoric acid and other compounds on fungi isolated from poultry feed. Anim. Feed Sci. Tech., 54: 217-226.

Marcos M. V., José, F., Machado, M., Sônia, C., Daróz de, M. and Mônica Maria de, A. 2004. Mixture of formic and propionic acid as additives in broiler feeds, Sci. Agric., 61: 371-375.

Mathew A. G., Sutton, A. L., Scheidt, A., Bforsyth, D. M., Patterson, J. A. and Kelly, D. T. 1991. Effect of a propionic acid containing feed additives on performance and intestinal microbial fermentation of ten weanling pig. A proceeding of $5^{\text {th }}$ International symposium on digestive physiology in pigs. Wageningen, Netherlands, Eaap Publication, No.54: pp.464-469. 
Bang. J. Anim. Sci. 2009, 38(1\&2)

Paul, S. K., Samanata, G., Halder, G. and Biswas, P. 2007. Effect of a combination of organic acid salts as antibiotic replacer on the performance and gut health of broiler chickens. Livestock Research and Rural Development, 19: 11.

Ronald, R.M. 1996. Effects of molds and their toxins on livestock performance. Anim. Feed Sci. Techn., 58: 77-89.

Roy, R. D., Edens, F. W., Parkhurst, C. R., Qureshi, M. A. and Havenstein, G. B. 2002. Influence of a propionic acid feed additive on performance of turkey poults with experimentally induced poult enteritis and mortality syndrome1. Poult. Sci., 81: 951-957.

Zou, X. T., Xu, Z. R., Wang, Y. M. and Din, J.W. 1997. Studies on the effect of nystatin as antifungal agents. Journal of Zhejiang Agricultural University, 23: 321-325. 